\title{
The association between antidepressant use and disturbances in glucose homeostasis: evidence from spontaneous reports
}

\author{
Hieronymus J. Derijks • Ronald H. B. Meyboom • \\ Eibert R. Heerdink • Fred H. P. De Koning • \\ Rob Janknegt • Marie Lindquist • Antoine C. G. Egberts
}

Received: 26 July 2007 / Accepted: 3 December 2007 / Published online: 15 January 2008

(C) The Author(s) 2007

\begin{abstract}
Objectives Depression is common in patients with diabetes, and the use of antidepressants may impair glycaemic control. We assessed the association between antidepressant use and hyper- and hypoglycaemia.

Methods Based on spontaneous reports listed in the World Health Organization (WHO) Adverse Drug Reaction Database, a case-control study was conducted. The study base consisted of all adverse drug reactions (ADRs)
\end{abstract}

Role of the funding source: No funding source was involved.

H. J. Derijks $(\bowtie) \cdot$ R. H. B. Meyboom • E. R. Heerdink •

F. H. P. De Koning • A. C. G. Egberts

Department of Pharmacoepidemiology and Pharmacotherapy,

Utrecht Institute for Pharmaceutical Sciences (UIPS),

Faculty of Science, Utrecht University,

P.O. Box 80082, 3508 TB Utrecht, The Netherlands

e-mail: h.j.derijks@uu.nl

H. J. Derijks $\cdot$ R. Janknegt

Department of Clinical Pharmacy, Orbis Medical Center,

P.O. Box 5500, 6130 MB Sittard, The Netherlands

R. H. B. Meyboom • M. Lindquist

The Uppsala Monitoring Centre,

WHO Collaborating Centre for International Drug Monitoring,

Stora Torget 3,

75320 Uppsala, Sweden

F. H. P. De Koning

Kring Apotheken Nederland,

P.O. Box 210, 5201 AE Den Bosch, The Netherlands

A. C. G. Egberts

Department of Clinical Pharmacy,

University Medical Center Utrecht,

P.O. Box 85500, 3508 GA Utrecht, The Netherlands ascribed to antidepressants, antipsychotics and benzodiazepines between 1969 and 2005. Cases were defined as reported ADRs classified as hyper- or hypoglycaemia and separated in different study populations. All other reports were considered as controls. Exposure to antidepressants was the primary determinant investigated. Benzodiazepines and antipsychotics were chosen as reference groups. Potential confounding factors, namely, age, gender, use of antidiabetic medication, use of hyper- or hypoglycaemiainducing comedication and reporting year, were determined on the index date. Multivariate logistic regression was used to evaluate the strength of the association, which was expressed as reporting odds ratios (RORs) with 95\% confidence intervals $(95 \% \mathrm{CI})$.

Results Overall, the use of antidepressants was associated with hyperglycaemia [ROR 1.52 (95\% CI: $1.20-1.93)$ ] and of hypoglycaemia [ROR 1.84 (95\% CI: $1.40-2.42)]$. The association with hyperglycaemia was most pronounced for antidepressants with affinity for the 5- $\mathrm{HT}_{2 \mathrm{c}}$ receptor, histamine- ${ }_{1}$ receptor and norepinephrinic (NE) reuptake transporter. The association with hypoglycaemia was most pronounced for antidepressants with affinity for the serotonin reuptake transporter.

Conclusion The results of this study strengthen the findings in individual case reports that the use of antidepressants is associated with disturbances in glucose homeostasis.

Keywords Hyperglycaemia · Hypoglycaemia . Antidepressive agents $\cdot$ Adverse drug Reaction reporting systems $\cdot$ WHO

\section{Introduction}

The use of psychotropic agents has been related to disturbances in glucose homeostasis. Antipsychotics in 
particular[1], especially the atypical antipsychotics clozapine and olanzapine, can cause hyperglycaemia, diabetes mellitus type 2, and other metabolic disturbances [2, 3]. Antidepressants may also interfere with blood glucose metabolism, paradoxically increasing the risk of both hyper- and hypoglycaemia [4-7]. However, evidence on the association of antidepressant use and impaired glucose homeostasis is more scarce and mainly originates from case reports and short-term trials with selected and small group of patients with comorbid diabetes mellitus.

Antidepressant use is common in patients with diabetes mellitus; several studies revealed that the risk of depression is twice as high among adults with chronic diabetes mellitus compared with the general population [8]. If antidepressants indeed interfere with glucose homeostasis in patients with diabetes mellitus, then this could further complicate glycaemic control, which is a limiting factor to prevent or delay microvascular complications [9-12] in the long term.

In order to contribute to the evidence base on the association between the use of antidepressants and hyper- and hypoglycaemia, we carried out a case-control study based on spontaneous reports of adverse drug reactions (ADRs) in the database of the international pharmacovigilance programme of the World Health Organization (WHO ADR database). In addition, we wanted to elucidate whether specific pharmacological properties could explain a potential influence on glucose homeostasis.

\section{Materials and methods}

\section{Setting}

The study was conducted within the database of the WHO Uppsala Monitoring Center (WHO UMC), Sweden. The WHO UMC receives summary clinical reports about individual suspected adverse reactions to pharmaceutical products submitted through National Pharmacovigilance Centers by 82 countries around the world, and the reports are heterogeneous with regards to source, documentation and relationship likelihood. The reports are submitted in an electronic format and stored in a central database: Vigibase. The programme was established in 1968. The WHO database holds 3.7 million records, making it the world's largest database of spontaneous ADRs. Details available about suspected ADRs are age, gender, reporting date, country, nature of the ADR, suspected drug(s), concomitantly used drug(s) and interacting drug(s). Drugs and suspected ADRs are respectively classified according to the Anatomical Therapeutic Chemical (ATC) classification system and the WHO Adverse Reaction Terminology (WHO-ART). All patient information is provided anonymously [13].
Study design and population

A nested case control design was used to evaluate the association between the use of antidepressants and hyperand hypoglycaemia. The base cohort consisted of all reports of ADRs in association with antidepressants, antipsychotics or benzodiazepines between January 1969 and January 2005. Reports were only included when data on gender were available and the patients were 18 years or older. Hyper- and hypoglycaemic reactions were separated in two different study populations. Cases were defined as reported ADRs classified as hyper- or hypoglycaemia. Hyperglycemia cases included all reports with preferred-Level terms diabetes mellitus, diabetes mellitus aggravated, diabetes mellitus reactivated, hyperglycaemia, ketosis, glucose intolerance abnormal, diabetic or glycosuria. Hypoglycaemia cases included all reports with preferred-level terms hypoglycaemia, hypoglycaemic reaction and coma hypoglycaemic. All reports containing other adverse event terms were considered as controls.

\section{Exposure}

Exposure to antidepressants was the primary determinant investigated and was defined as the reporting of antidepressants as a suspected, interacting or concomitant drug for an ADR. Exposure to antidepressants was further subclassified into four clusters based upon pharmacological binding properties of six common transporter or receptor sites: the 5-HT (serotonin) reuptake transporter, norepinephrine reuptake transporter, $\mathrm{M}_{3}$ receptor, $\mathrm{H}_{1}$ receptor, $\alpha_{1}$ receptor and 5- $\mathrm{HT}_{2 \mathrm{c}}$ receptor [14]. When two different antidepressants were reported in the same report they could not be classified into one of the four clusters, and the report was classified into a fifth classification category: two antidepressants. Benzodiazepines were chosen as a negative comparator group for hypo- and hyperglycaemia because the use of benzodiazepines has not been associated with hyper- or hypoglycaemia, and patients using benzodiazepines are more likely to have similar baseline characteristics as patients using antidepressants because both benzodiazepines and antidepressants belong to the group of psychotropic agents. Antipsychotics (which are associated with a higher risk of hyperglycaemia but not hypoglycaemia [2, 3]) were chosen as a positive comparator group for hyperglycaemia and as a negative comparator group for hypoglycaemia. Exposure to antipsychotics and benzodiazepines was defined as the reporting of respectively antipsychotics and benzodiazepines as a suspected, interacting or concomitant drug for an ADR. Reports with two or more types of drugs (antidepressant, benzodiazepine or antipsychotic agent) within the same report were excluded. 
Potential confounding factors

The following covariates were studied to adjust for potential confounding: age, gender, use of diabetic medication, use of hyper- or hypoglycaemia-inducing comedication and reporting year. The use of antidiabetic medication and of hyper- or hypoglycaemia-inducing comedication was defined as the reporting of one of these drugs as a suspected, interacting or concomitant drug for an ADR. Hyper- and hypoglycaemiainducing comedications were identified by a search in literature. For details we refer to references [15-17].

Data analysis

For both cases and controls, the prevalence of each characteristic on the index date (reporting date of the ADR) was determined. Student's $t$ test was performed to assess the significance of differences in the mean of continuous variables between cases and controls. Differences in the proportions of categorical variables of the baseline characteristics between cases and controls were tested for significance by unconditional logistic regression and expressed as $p$ values. The strength of the association between the use of antidepressants or antipsychotics and hypo- or hyperglycaemia was evaluated with unconditional logistic regression analysis and expressed as reporting odds ratios (ROR) with $95 \%$ confidence intervals $(95 \% \mathrm{CI})$. Besides age and gender, covariates were included in the unconditional regression model if they were either independently significantly associated with hypo- or hyperglycaemia or induced a change in the crude OR for current use of antidepressants of at least $10 \%$ [18]. Unless antidiabetic medication fulfilled the conditions as a covariate to correct for in the logistic model, we excluded this antidiabetic medication as a covariate from analysis because information about diabetic comedication was incomplete. Exclusion of antidiabetic medication from the model, however, did not significantly change the primary outcome. All statistical calculations were carried out with the SPSS statistical package (version 12.0).

\section{Results}

\section{Hyperglycaemia}

The base cohort consisted of 192,292 reports. From this cohort, 1,953 (1.02\%) reports were identified as cases and $190,339(98.98 \%)$ as controls. Table 1 describes details of demographic and medical characteristics of the study population. Mean age was statistically different among the cases and the controls. Cases were more frequently male than were controls, and the use of diabetic medication, use of hyper- or hypoglycaemia-inducing comedication was more frequently reported in cases than in controls. Finally,
Table 1 Baseline characteristics of the hyperglycaemia study population

\begin{tabular}{|c|c|c|c|c|c|}
\hline \multirow{2}{*}{$\begin{array}{l}\text { Risk factor } \\
\text { Mean age (years) }\end{array}$} & \multicolumn{2}{|c|}{$\begin{array}{l}\text { Cases } \\
\text { (hyperglycaemia) } \\
(n=1,953)\end{array}$} & \multicolumn{2}{|c|}{$\begin{array}{l}\text { Controls (no } \\
\text { hyperglycaemia) } \\
(n=190,339)\end{array}$} & $P$ value \\
\hline & 45.1 & & 47.3 & & $<0.001$ \\
\hline \multicolumn{6}{|l|}{ Age category } \\
\hline $18-35$ years & 568 & $(29.1 \%)$ & 57,220 & $(30.1 \%)$ & Reference \\
\hline $36-55$ years & 958 & $(49.1 \%)$ & 75,546 & $(39.7 \%)$ & $<0.001$ \\
\hline$>55$ years & 427 & $(21.9 \%)$ & 57,573 & $(30.2 \%)$ & $<0.001$ \\
\hline \multicolumn{6}{|l|}{ Gender } \\
\hline Male & 1,138 & $(58.3 \%)$ & 76,024 & $(39.9 \%)$ & Reference \\
\hline Female & 815 & $(41.7 \%)$ & 114,315 & $(60.1 \%)$ & $<0.001$ \\
\hline \multicolumn{6}{|l|}{ Diabetic comedication } \\
\hline No diabetic comedication & 1,648 & $(84.4 \%)$ & 187,674 & $(98.6 \%)$ & Reference \\
\hline Insulin & 150 & $(7.7 \%)$ & 923 & $(0.5 \%)$ & $<0.001$ \\
\hline Oral antidiabetics & 131 & $(6.7 \%)$ & 1,647 & $(0.9 \%)$ & $<0.001$ \\
\hline Oral antidiabetics + insulin & 24 & $(1.2 \%)$ & 95 & $(0.0 \%)$ & $<0.001$ \\
\hline \multicolumn{6}{|c|}{ Нypo- or hyperglycaemia-inducing comedication use } \\
\hline $\begin{array}{l}\text { No comedication associated with hypo- or } \\
\text { hyperglycaemia }\end{array}$ & 1,610 & $(82.4 \%)$ & 150,112 & $(78.9 \%)$ & Reference \\
\hline $\begin{array}{l}\text { Comedication associated with hypo- } \\
\text { or hyperglycaemia }\end{array}$ & 343 & $(17.6 \%)$ & 40,227 & $(21.1 \%)$ & $<0.001$ \\
\hline \multicolumn{6}{|l|}{ Reporting year } \\
\hline $1968-1990$ & 92 & $(4.7 \%)$ & 36,644 & $(19.3 \%)$ & Reference \\
\hline $1991-2000$ & 713 & $(36.5 \%)$ & 102,266 & $(53.7 \%)$ & $<0.001$ \\
\hline $2001-2005$ & 1,148 & $(58.8 \%)$ & 51,429 & $(27.0 \%)$ & $<0.001$ \\
\hline
\end{tabular}


cases were more frequently reported within the period 2001-2005 than were the controls. Table 2 shows the association between the use of antidepressants and hyperglycaemia. Overall, use of antidepressants was associated with hyperglycaemia [ROR ${ }_{\text {adj: }}: 1.52$ (95\% CI: 1.20-1.93)]. Looking at classification according to the pharmacological properties of antidepressants, antidepressants from cluster 1 (sertraline, fluvoxamine, paroxetine, venlafaxine, fluoxetine, citalopram and clomipramine) [ROR adj: 1.43 (95\% CI: $1.11-$ 1.83)], cluster 2 (amitriptyline, doxepin and imipramine) [ROR ${ }_{\text {adj: }} 1.91$ (95\% CI: 1.30-2.81)] and cluster 3 (maprotiline, nortriptyline, mianserin and mirtazapine) $\left[\mathrm{ROR}_{\mathrm{adj}}: 1.93\right.$ (95\% CI: 1.32-2.83)] were positively associated with hyperglycaemia. The association was most pronounced for antidepressants from cluster 2 and cluster 3 with corresponding binding properties for the $5-\mathrm{HT}_{2 \mathrm{c}}$ receptor, $\mathrm{H}_{1}$ receptor, respectively, norepinephrinic (NE) reuptake transporter. Also, there is support for a different association of hyperglycaemia and antidepressants in cluster 1 compared with antidepressants in clusters 2 or 3 because the point estimates for antidepressants in cluster 2 or 3 are not included in the confidence interval for cluster 1 antidepressants. No association was found between hyperglycaemia and antidepressants from cluster 4 (trazodone). The association of hyperglycaemia was most pronounced after more than 1 year of antidepressant use [ROR $\mathrm{Rdj}_{\mathrm{aj}}: 2.05$ (95\% CI: 1.27-3.31)]. Antipsychotics were associated with a more than sixfold increased risk of hyperglycaemia $\left[\mathrm{ROR}_{\mathrm{adj}}\right.$ : $6.40(95 \% \mathrm{CI}$ : 5.11-7.99)].
Hypoglycaemia

The base cohort consisted of 190,864 reports. From this cohort, $525(0.28 \%)$ reports were identified as cases and $190,339(99.72 \%)$ as controls. Table 3 describes details of demographic and medical characteristics of the study population. Mean age was statistically significantly higher among cases than among controls. Male and female were equally divided among the cases and controls. The use of diabetic medication, use of hyper- or hypoglycaemiainducing comedication was more frequently reported in cases than in controls. Finally, cases were more frequently reported within the period 2001-2005 than were controls. Table 4 shows the association between the use of antidepressants and hypoglycaemia. Use of antidepressants was associated with hypoglycaemia $\left[\mathrm{ROR}_{\mathrm{adj}}: 1.84(95 \% \mathrm{CI}\right.$ : 1.04-2.42)]. Looking at classification according to the pharmacological properties of antidepressants, antidepressants from cluster 1 (sertraline, fluvoxamine, paroxetine, venlafaxine, fluoxetine, citalopram and clomipramine) $\left[\mathrm{ROR}_{\mathrm{adj}}\right.$ : 2.00 (95\% CI: 1.51-2.65)] and cluster 2 (amitriptyline, doxepin and imipramine) [ROR adj: 2.19 (95\% CI: 1.44 3.33)], with corresponding binding properties for the serotonin reuptake transporter, were positively associated with hypoglycaemia. No association was found between hypoglycaemia and antidepressants from cluster 3 (maprotiline, nortriptyline, mianserin and mirtazapine) and cluster 4 (trazodone). The association between hypoglycaemia and the use of antidepressants from cluster 1 or 2 and anti-

Table 2 Risk of hyperglycaemia associated with use of psychotropic drugs

\begin{tabular}{|c|c|c|c|c|c|c|c|c|}
\hline \multirow{2}{*}{$\begin{array}{l}\text { Risk factor } \\
\text { Psychotropic agent }\end{array}$} & \multicolumn{2}{|c|}{$\begin{array}{l}\text { Cases (hyperglycaemia) } \\
(n=1953)\end{array}$} & \multicolumn{2}{|c|}{$\begin{array}{l}\text { Controls (no hyperglycaemia) } \\
(n=190,339)\end{array}$} & \multicolumn{2}{|c|}{ ROR crude $(95 \% \mathrm{CI})$} & \multicolumn{2}{|c|}{ ROR adjusted $*(95 \% \mathrm{CI})$} \\
\hline & & & & & & & & \\
\hline Benzodiazepines & 86 & $(4.4 \%)$ & 32,487 & $(17.1 \%)$ & 1.00 & (Reference) & 1.00 & (Reference) \\
\hline Antidepressants & 412 & $(21.1 \%)$ & 101,198 & $(53.2 \%)$ & 1.54 & $(1.22-1.94)$ & 1.52 & $(1.20-1.93)$ \\
\hline Antipsychotics & 1,455 & $(74.5 \%)$ & 56,654 & $(29.8 \%)$ & 9.70 & $(7.80-12.06)$ & 6.40 & $(5.11-7.99)$ \\
\hline \multicolumn{9}{|c|}{ Antidepressant use (classification according to pharmacological properties) } \\
\hline Benzodiazepines & 86 & $(17.3 \%)$ & 32,487 & $(24.3 \%)$ & 1.00 & (Reference) & 1.00 & (Reference) \\
\hline Cluster $1 \mathrm{AD}$ & 296 & $(59.4 \%)$ & 74,931 & $(56.1 \%)$ & 1.49 & $(1.17-1.90)$ & 1.43 & $(1.11-1.83)$ \\
\hline Cluster $2 \mathrm{AD}$ & 37 & $(7.4 \%)$ & 8,541 & $(6.4 \%)$ & 1.64 & $(1.11-2.41)$ & 1.91 & $(1.30-2.81)$ \\
\hline Cluster $3 \mathrm{AD}$ & 39 & $(7.8 \%)$ & 8,230 & $(6.2 \%)$ & 1.79 & $(1.23-2.62)$ & 1.93 & $(1.32-2.83)$ \\
\hline Cluster 4 AD & 6 & $(1.2 \%)$ & 2,314 & $(1.7 \%)$ & 0.98 & $(0.43-2.24)$ & 1.07 & $(0.47-2.45)$ \\
\hline 2 antidepressants & 34 & $(6.8 \%)$ & 7,182 & $(5.4 \%)$ & 1.79 & $(1.20-2.66)$ & 1.64 & $(1.10-2.44)$ \\
\hline \multicolumn{9}{|c|}{ Duration of antidepressant use } \\
\hline Benzodiazepines & 86 & $(33.2 \%)$ & 32,487 & $(40.2 \%)$ & 1.00 & (Reference) & 1.00 & (Reference) \\
\hline $0-1$ year & 151 & $(58.3 \%)$ & 44,649 & $(55.2 \%)$ & 1.28 & $(0.98-1.67)$ & 1.29 & $(0.98-1.69)$ \\
\hline$>1$ year & 22 & $(8.5 \%)$ & 3,738 & $(4.6 \%)$ & 2.22 & $(1.39-3.56)$ & 2.05 & $(1.27-3.31)$ \\
\hline
\end{tabular}

$R O R$ reporting odds ratio, $C I$ confidence interval, $A D$ antidepressants

Cluster 1 antidepressants: sertraline, fluvoxamine, paroxetine, venlafaxine, fluoxetine, citalopram, clomipramine, Cluster 2 antidepressants: amitriptyline, doxepin, imipramine, Cluster 3 antidepressants: maprotiline, nortriptyline, mianserin, mirtazapine, Cluster 4 antidepressants: trazodone

* Adjusted for age, gender, reporting year, hypo- or hyperglycaemia-inducing comedication 
Table 3 Baseline characteristics of the hypoglycaemia study population

\begin{tabular}{|c|c|c|c|c|c|}
\hline \multirow{2}{*}{$\begin{array}{l}\text { Risk factor } \\
\text { Mean age (years) }\end{array}$} & \multicolumn{2}{|c|}{$\begin{array}{l}\text { Cases } \\
\text { (hypoglycaemia) } \\
(n=525)\end{array}$} & \multicolumn{2}{|c|}{$\begin{array}{l}\text { Controls (no } \\
\text { hypoglycaemia) } \\
(n=190339)\end{array}$} & $P$ value \\
\hline & 50.9 & & 47.3 & & 0.043 \\
\hline \multicolumn{6}{|l|}{ Age category } \\
\hline $18-35$ years & 115 & $(21.9 \%)$ & 57,220 & $(30.1 \%)$ & Reference \\
\hline $36-55$ years & 216 & $(41.1 \%)$ & 75,546 & $(39.7 \%)$ & 0.002 \\
\hline$>55$ years & 194 & $(37.0 \%)$ & 57,573 & $(30.2 \%)$ & $<0.001$ \\
\hline \multicolumn{6}{|l|}{ Gender } \\
\hline Male & 207 & $(39.4 \%)$ & 76,024 & $(39.9 \%)$ & Reference \\
\hline Female & 318 & $(60.6 \%)$ & 114,315 & $(60.1 \%)$ & 0.811 \\
\hline \multicolumn{6}{|l|}{ Diabetic comedication } \\
\hline No diabetic comedication & 336 & $(64.0 \%)$ & 187,674 & $(98.6 \%)$ & Reference \\
\hline Insulin & 128 & $(24.4 \%)$ & 923 & $(0.5 \%)$ & $<0.001$ \\
\hline Oral antidiabetics & 50 & $(9.5 \%)$ & 1,647 & $(0.9 \%)$ & $<0.001$ \\
\hline Oral antidiabetics + insulin & 11 & $(2.1 \%)$ & 95 & $(0.0 \%)$ & $<0.001$ \\
\hline \multicolumn{6}{|c|}{ Hypo- or hyperglycaemia-inducing comedication use } \\
\hline $\begin{array}{l}\text { No comedication associated with hypo- or } \\
\text { hyperglycaemia }\end{array}$ & 378 & $(72.0 \%)$ & 150,112 & $(78.9 \%)$ & Reference \\
\hline $\begin{array}{l}\text { Comedication associated with hypo- or } \\
\text { hyperglycaemia }\end{array}$ & 147 & $(28.0 \%)$ & 40,227 & $(21.1 \%)$ & $<0.001$ \\
\hline \multicolumn{6}{|l|}{ Reporting year } \\
\hline $1968-1990$ & 69 & $(13.1 \%)$ & 36,644 & $(19.3 \%)$ & Reference \\
\hline $1991-2000$ & 296 & $(56.4 \%)$ & 102,266 & $(53.7 \%)$ & 0.001 \\
\hline $2001-2005$ & 160 & $(30.5 \%)$ & 51,429 & $(27.0 \%)$ & $<0.001$ \\
\hline
\end{tabular}

depressants from cluster 3 is different, because the point estimates for antidepressants in cluster 1 or 2 are not included in the CI for antidepressants in cluster 3. Antipsychotics were not associated with a higher risk of hypoglycaemia $\left[\mathrm{ROR}_{\mathrm{adj}}\right.$ : 0.84 (95\% CI: 0.60-1.19)].

\section{Discussion}

Overall, the use of antidepressants was associated with hyperglycaemia [ROR ${ }_{\mathrm{adj}}: 1.52$ (95\% CI: 1.20-1.93)] and hypoglycaemia [ROR $\left.\mathrm{Rdj}_{\mathrm{a}}: 1.84(95 \% \mathrm{CI}: 1.40-2.42)\right]$ com-

Table 4 Risk of hypoglycaemia associated with use of psychotropic drugs

\begin{tabular}{|c|c|c|c|c|c|c|c|c|}
\hline \multirow{2}{*}{$\begin{array}{l}\text { Risk factor } \\
\text { Psychotropic agents }\end{array}$} & \multicolumn{2}{|c|}{$\begin{array}{l}\text { Cases (hypoglycaemia) } \\
(n=525)\end{array}$} & \multicolumn{2}{|c|}{$\begin{array}{l}\text { Controls (no hypoglycaemia) } \\
(n=190339)\end{array}$} & \multicolumn{2}{|c|}{ ROR crude $(95 \% \mathrm{CI})$} & \multicolumn{2}{|c|}{ ROR adjusted $*(95 \% \mathrm{CI})$} \\
\hline & & & & & & & & \\
\hline Benzodiazepines & 64 & $(12.2 \%)$ & 32,487 & $(17.1 \%)$ & 1.00 & (Reference) & 1.00 & (Reference) \\
\hline Antidepressants & 370 & $(70.5 \%)$ & 101,198 & $(53.2 \%)$ & 1.86 & $(1.42-2.42)$ & 1.84 & $(1.40-2.42)$ \\
\hline Antipsychotics & 91 & $(17.3 \%)$ & 56,654 & $(29.8 \%)$ & 0.82 & $(0.59-1.12)$ & 0.84 & $(0.60-1.19)$ \\
\hline \multicolumn{9}{|c|}{ Antidepressant use (classification according to pharmacological properties) } \\
\hline Benzodiazepines & 64 & $(14.7 \%)$ & 32,487 & $(24.3 \%)$ & 1.00 & (Reference) & 1.00 & (Reference) \\
\hline Cluster $1 \mathrm{AD}$ & 298 & $(68.7 \%)$ & 74,931 & $(56.1 \%)$ & 2.02 & $(1.54-2.65)$ & 2.00 & $(1.51-2.65)$ \\
\hline Cluster 2 AD & 34 & $(7.8 \%)$ & 8,541 & $(6.4 \%)$ & 2.02 & $(1.33-3.07)$ & 2.19 & $(1.44-3.33)$ \\
\hline Cluster 3 AD & 14 & $(3.2 \%)$ & 8,230 & $(6.2 \%)$ & 0.86 & $(0.48-1.54)$ & 0.89 & $(0.50-1.60)$ \\
\hline Cluster 4 AD & 7 & $(1.6 \%)$ & 2,314 & $(1.7 \%)$ & 1.54 & $(0.70-3.35)$ & 1.62 & $(0.74-3.54)$ \\
\hline 2 antidepressants & 17 & $(3.9 \%)$ & 7,182 & $(5.4 \%)$ & 1.20 & $(0.70-2.05)$ & 1.16 & $(0.68-2.00)$ \\
\hline \multicolumn{9}{|c|}{ Duration of antidepressant use } \\
\hline Benzodiazepines & 64 & $(27.4 \%)$ & 32,487 & $(40.2 \%)$ & 1.00 & (Reference) & 1.00 & (Reference) \\
\hline $0-1$ year & 155 & $(66.2 \%)$ & 44,649 & $(55.2 \%)$ & 1.76 & $(1.32-2.36)$ & 1.73 & $(1.28-2.33)$ \\
\hline$>1$ year & 15 & $(6.4 \%)$ & 3,738 & $(4.6 \%)$ & 2.04 & $(1.16-3.58)$ & 1.84 & $(1.04-3.27)$ \\
\hline
\end{tabular}

$R O R$ reporting odds ratio, $C I$ confidence interval, $A D$ antidepressants

Cluster 1 antidepressants: sertraline, fluvoxamine, paroxetine, venlafaxine, fluoxetine, citalopram, clomipramine, Cluster 2 antidepressants: amitriptyline, doxepin, imipramine, Cluster 3 antidepressants: maprotiline, nortriptyline, mianserin, mirtazapine, Cluster 4 antidepressants: trazodone

* Adjusted for age, gender, reporting year, hypo- or hyperglycaemia-inducing comedication 
pared with benzodiazepines. The association of hyperglycaemia was most pronounced for antidepressants with corresponding binding properties for the $5-\mathrm{HT}_{2 \mathrm{c}}$ receptor, $\mathrm{H}_{1}$ receptor and NE reuptake transporter. The association of hypoglycaemia, on the other hand, was most pronounced for antidepressants with corresponding binding properties for the serotonin reuptake transporter.

Hyperglycemia is primarily a symptom of diabetes mellitus and a result of absolute or relative insulin deficiency. Nondiabetic hyperglycaemia can be caused by eating disorders, acute stress (such as stroke or myocardial infarction) and the use of certain medications [19], particularly in prediabetic patients. Evidence from trials of antidepressantassociated hyperglycaemia in human is scarce. Moosa et al. randomised a group of nondiabetic depressed women using imipramine and fluoxetine for 3 months. In the imipramine group, body mass index (BMI) increased and insulin secretion and insulin resistance decreased during followup [5]. Lustman et al. studied a group of diabetic patients treated with nortriptyline for 8 weeks. Nortriptyline worsened glycaemic control, whereas depression improvement had an independent beneficial effect on glycated haemoglobin $\left(\mathrm{HbA}_{1 \mathrm{C}}\right)$, which is an aggregate measure of glycaemic control over the 120-day period before testing [20]. Laimer et al. observed a group of nondiabetic depressed women treated with mirtazapine for 6 weeks. They found that treatment with mirtazapine was associated with a significant increase in body weight, body fat mass and leptin concentration [21].

We found that the association between hyperglycaemia and use of antidepressants was most pronounced for antidepressants from cluster 2 and cluster 3 with corresponding binding properties for the NE reuptake transporter, $5-\mathrm{HT}_{2 \mathrm{c}}$ receptor and $\mathrm{H}_{1}$ receptor. From a pharmacological point of view, inhibition of the NE reuptake transporter increases synaptic NE disposal directly by stimulating glycogenolysis and gluconeogenesis, resulting in raised blood glucose levels [22]. It is also postulated that central blockade of the $\mathrm{H}_{1}$ receptor and $5-\mathrm{HT}_{2 \mathrm{c}}$ receptor stimulates energy intake by increasing appetite with a resultant positive energy balance, thereby causing weight gain [23-25]. Weight gain may result in insulin resistance and increase the risk of hyperglycaemia. Some of the antidepressants from cluster 2 and cluster 3 also have high affinity for the $\mathrm{M}_{3^{-}}$, and $\alpha-1$ adrenergic receptors, causing side effects such as a dry mouth, leading to drinking large quantities of (high-calorie) soft drinks. Both effects on food intake may influence the diabetic's ability to follow a controlled diet. In addition, peripheral blockade of $\mathrm{M}_{3}$ receptors in beta cells results in suppression of insulin secretion and raised leptin levels (also inhibiting insulin secretion by the pancreas), thereby increasing the risk of hyperglycaemia $[5,26]$.
In general, hypoglycaemia can be caused by regulatory, enzymatic or substrate defects. Iatrogenic hypoglycaemia in patients with diabetes mellitus can be seen as the result of the interplay of relative or absolute therapeutic insulin excess and compromised glucose counterregulation [22], and attenuation of warning signals can contribute to hypoglycaemia. Insulin excess, for example, occurs when sensitivity to insulin is increased or endogenous glucose production is decreased. In different studies in patients with type 2 diabetes mellitus and nondiabetic patients, the use of fluoxetine and the serotonergic anorectic agent fenfluramine increased insulin sensitivity in the short term, thereby increasing the risk on hypoglycaemia [27-31]. We found that the association between hypoglycaemia and the use of antidepressants was most pronounced for antidepressants from cluster 1 and cluster 2 with corresponding binding properties for the serotonin reuptake inhibitor. These findings correspond with earlier observations that serotonergic agents may cause hypoglycaemia.

This study has several limitations. First, it could be biased by confounding by indication. We did not have information concerning the indications for use of the drugs. Therefore, we were not able to identify whether hyper- or hypoglycaemia was caused by a pharmacological effect of antidepressants or by underlying diseases (i.e. depression). It is known that depressive symptom severity in diabetic patients is a risk factor for poor glycaemic control, generally characterised by higher glucose levels $[32,33]$. There is evidence that recovery from depression improves glycaemic control, not by inducing severe hypoglycaemic reactions but by slight decreases in $\mathrm{HbA}_{1 \mathrm{C}}$. In two placebo-controlled randomised clinical trials $[34,35]$ and one open study [36], depressed diabetic patients were treated with fluoxetine, paroxetine and sertraline, respectively, for 8-10 weeks. After the study period, the treatment groups showed a trend towards a better glycaemic control expressed as a decrease in $\mathrm{HbA}_{1 \mathrm{C}}$. These studies, however, were not designed to reveal the mechanism and to distinguish between a depressionrelated effect or a pharmacological effect of antidepressants.

Second, cases are likely based on more pronounced symptomatic episodes of hyper- and hypoglycaemia. Episodes of asymptomatic hyper- or hypoglycaemia, or hyper- or hypoglycaemia self-treated by injection of insulin or intake of carbohydrates or injection of glucagon are likely to go unreported. To elucidate what happens on the microlevel and in the short term, studies with more sensitive markers are needed; for example, by analysing dosing patterns of insulin and oral antidiabetics from diabetic diaries in patients starting antidepressant treatment.

Third, we did not have explicit information about the type of diabetes, which it is known to be an important risk factor for hyper- and hypoglycaemia. We took into account 
patient age and the type of diabetic medication used. The use of diabetic medication, however, was not completely recorded. Sensitivity analysis with or without adjustment for diabetic medication did not change the overall outcomes.

Fourth, ADRs were reported on a voluntary basis and represent only a fraction $(<10 \%)$ of the actual adverse events that occurred $[37,38]$. ADRs more likely to be reported than others, if they are, include: (1) severe ADRs (which is discussed above), (2) ADRs not listed in the summary of product characteristics and (3) ADRs of relatively new drugs [37, 39]. To adjust for possible time trends of reporting, we included the reporting year in our multivariate logistic regression model.

Fifth, the classification model of antidepressants based on pharmacological properties deals with several restrictions. In the model, it is assumed that all antidepressants are full agonists or antagonists for all receptor types and the model does not account for active metabolites. However, in contrast to the classical classification of antidepressants, this pharmacodynamic classification system provides a rational and objective basis in pharmacovigilance in the search for high-risk antidepressants for specific ADRs and may help unravel the mechanism behind these ADRs.

Finally, the inclusion of reports where the drug was reported as interacting may be questionable, since this term is often used for pharmacokinetic drug interactions and would therefore have less relevance for a pharmacodynamic effect of the drug. The reporter, however, may not always be aware of a possible association between the use antidepressants and disturbances in glucose homeostasis and therefore classify the antidepressant as an interacting or concomitant drug for an ADR. We therefore included all reports of drugs classified as suspected, interacting or concomitant for an ADR. Separate analyses for the suspected ADRs were performed, but this did not change the overall outcome.

The strength of this study is that this is the first controlled study to assess the association between antidepressant use and hyper- and hypoglycaemia in a large population based upon spontaneous reporting in medical practice. We were able to identify antidepressants that were more likely to cause hyper- and hypoglycaemia. Finally, we compared the association between antidepressant use and hyperglycaemia with the association between antipsychotic use and hyperglycaemia, which is a well-established and clinically relevant side effect of antipsychotics.

In conclusion, the results of this study strengthen the findings of individual case reports that the use of antidepressants is associated with disturbances in glucose homeostasis. The association between antidepressant use and hyperglycaemia was most pronounced for antidepressants with high affinity for the NE reuptake transporter, 5- $\mathrm{HT}_{2 \mathrm{c}}$ receptor and $\mathrm{H}_{1}$ receptor. The association was less strong, however, compared with the reporting of hyperglycaemia associated with antipsychotics. The association between antidepressant use and hypoglycaemia, on the other hand, was most pronounced for antidepressants, with a high affinity for the serotonin reuptake transporter. It is important for diabetic patients to know that the use of antidepressants can inadvertently interfere with strict blood glucose self-monitoring and may precipitate or worsen episodes of either hyper- or hypoglycaemia. A follow-up study is needed to confirm the associations we found in our study and to translate these associations to the risk of antidepressants on disturbances in glucose homeoastasis.

Open Access This article is distributed under the terms of the Creative Commons Attribution NonCommercial License which permits any noncommercial use, distribution, and reproduction in any medium, provided the original author(s) and source are credited.

\section{References}

1. Hiles BW (1956) Hyperglycemia and glucosuria following chlorpromazine therapy. JAMA 160:1651

2. Gianfrancesco F, White R, Wang RH, Nasrallah HA (2003) Antipsychotic-induced type 2 diabetes: evidence from a large health plan database. J Clin Psychopharmacol 23(4):328-335

3. Miller EA, Leslie DL, Rosenheck RA (2005) Incidence of newonset diabetes mellitus among patients receiving atypical neuroleptics in the treatment of mental illness: evidence from a privately insured population. J Nerv Ment Dis 193(6):387-395

4. Goodnick PJ, Henry JH, Buki VM (1995) Treatment of depression in patients with diabetes mellitus. J Clin Psychiatry 56(4):128-136

5. Moosa MY, Panz VR, Jeenah FY, Joffe BI (2003) African women with depression: the effect of imipramine and fluoxetine on body mass index and leptin secretion. J Clin Psychopharmacol 23(6):549-552

6. McIntyre RS, Soczynska JK, Konarski JZ, Kennedy SH (2006) The effect of antidepressants on glucose homeostasis and insulin sensitivity: synthesis and mechanisms. Expert Opin Drug Saf 5(1):157-168

7. Derijks HJ, De Koning FH, Meyboom RH, Heerdink ER, Spooren PF, Egberts AC (2005) Impaired glucose homeostasis after imipramine intake in a diabetic patient. J Clin Psychopharmacol 25(6):621-623

8. Anderson RJ, Freedland KE, Clouse RE, Lustman PJ (2001) The prevalence of comorbid depression in adults with diabetes: a meta-analysis. Diabetes Care 24(6):1069-1078

9. DCCT (1993) The effect of intensive treatment of diabetes on the development and progression of long-term complications in insulindependent diabetes mellitus. The Diabetes Control and Complications Trial Research Group. N Engl J Med 329(14):977-986

10. Intensive blood-glucose control with sulphonylureas or insulin compared with conventional treatment and risk of complications in patients with type 2 diabetes (UKPDS 33). UK Prospective Diabetes Study (UKPDS) Group. Lancet 352(9131):837-853

11. Effect of intensive blood-glucose control with metformin on complications in overweight patients with type 2 diabetes (UKPDS 34). UK Prospective Diabetes Study (UKPDS) Group. Lancet 352(9131):854-865

12. Stratton IM, Adler AI, Neil HA, Matthews DR, Manley SE, Cull CA et al (2000) Association of glycaemia with macrovascular and microvascular complications of type 2 diabetes (UKPDS 35): prospective observational study. BMJ 321(7258):405-412 
13. Anonymous. International monitoring of adverse reactions to drugs. Adverse reaction terminology. Uppsala: WHO Collaborating Centre for International Drug Monitoring. 1995.

14. Derijks HJ, Heerdink ER, Janknegt R, De Koning GH, Olivier B, Loonen AJ, Egberts AC (2007) Visualizing pharmacological activities of antidepressant: a novel approach. Basic Clin Pharmacol Toxicol 101 (s1):105

15. Pandit MK, Burke J, Gustafson AB, Minocha A, Peiris AN (1993) Drug-induced disorders of glucose tolerance. Ann Intern Med 118 (7):529-539

16. Dwyer DS, Bradley RJ, Kablinger AS, Freeman AM 3rd (2001) Glucose metabolism in relation to schizophrenia and antipsychotic drug treatment. Ann Clin Psychiatry 13(2):103-113

17. Herings RM, de Boer A, Stricker BH, Leufkens HG, Porsius A (1995) Hypoglycaemia associated with use of inhibitors of angiotensin converting enzyme. Lancet 345(8959):1195-1198

18. Greenland S (1989) Modeling and variable selection in epidemiologic analysis. Am J Public Health 79(3):340-349

19. Luna B, Feinglos MN (2001) Drug-induced hyperglycemia. JAMA 286(16):1945-1948

20. Lustman PJ, Griffith LS, Clouse RE, Freedland KE, Eisen SA, Rubin EH, et al (1997) Effects of nortriptyline on depression and glycemic control in diabetes: results of a double-blind, placebocontrolled trial. Psychosom Med 59(3):241-250

21. Laimer M, Kramer-Reinstadler K, Rauchenzauner M, LechnerSchoner T, Strauss R, Engl J et al (2006) Effect of mirtazapine treatment on body composition and metabolism. J Clin Psychiatry 67(3):421-424

22. Larsen PR, Kronenberg MN, Melmed S, Polonsky KS (2003) Williams textbook of endocrinology, 10 edn. Saunders, Philadelphia

23. Tecott LH, Sun LM, Akana SF, Strack AM, Lowenstein DH, Dallman MF et al (1995) Eating disorder and epilepsy in mice lacking 5-HT2c serotonin receptors. Nature 374(6522):542-546

24. Wirshing DA, Wirshing WC, Kysar L, Berisford MA, Goldstein D, Pashdag J, et al (1999) Novel antipsychotics: comparison of weight gain liabilities. J Clin Psychiatry 60(6):358-363

25. Mulder H, Franke B, Van der Beek A, Arends J, Wilmink FW, Egberts AC et al (2006) The association between HTR2C polymorphisms and obesity in psychiatric patients using antipsychotics: a cross-sectional study. Pharmacogenomics J 7 (5):318-324

26. Gilon P, Henquin JC (2001) Mechanisms and physiological significance of the cholinergic control of pancreatic beta-cell function. Endocr Rev 22(5):565-604
27. Potter van Loon BJ, Radder JK, Frolich M, Krans HM, Zwinderman AH, Meinders AE (1992) Fluoxetine increases insulin action in obese nondiabetic and in obese non-insulindependent diabetic individuals. Int J Obes Relat Metab Disord 16(2):79-85

28. Araya V, Contreras P, Aguirre C, Depix MS, Zura ML (1995) The effect of fluoxetine on insulin resistance in non diabetic obese patients. Rev Med Chil 123(8):943-947

29. Scheen AJ, Paolisso G, Salvatore T, Lefebvre PJ (1991) Improvement of insulin-induced glucose disposal in obese patients with NIDDM after 1-wk treatment with d-fenfluramine. Diabetes Care 14(4):325332

30. Gray DS, Fujioka K, Devine W (1992) Fluoxetine in the treatment of the obese diabetic. Int J Obesity 16(2):79-85

31. Pestell RG, Crock PA, Ward GM (1989) fenfluramine increases action in patients with NIDDM. Diabetes Care 12:252-258

32. Van der Does FE, De Neeling JN, Snoek FJ, Kostense PJ, Grootenhuis PA, Bouter LM et al (1996) Symptoms and wellbeing in relation to glycemic control in type II diabetes. Diabetes Care 19(3):204-210

33. Van Tilburg MA, McCaskill CC, Lane JD, Edwards CL, Bethel A, Feinglos MN, et al (2001) Depressed mood is a factor in glycemic control in type 1 diabetes. Psychosom Med 63(4): 551-555

34. Lustman PJ, Freedland KE, Griffith LS, Clouse RE (2000) Fluoxetine for depression in diabetes: a randomized double-blind placebo-controlled trial. Diabetes Care 23(5):618-623

35. Paile-Hyvarinen M, Wahlbeck K, Eriksson JG (2003) Quality of life and metabolic status in mildly depressed women with type 2 diabetes treated with paroxetine: a single-blind randomised placebo controlled trial. BMC Fam Pract 4:7

36. Goodnick PJ, Kumar A, Henry JH, Buki VM, Goldberg RB (1997) Sertraline in coexisting major depression and diabetes mellitus. Psychopharmacol Bull 33(2):261-264

37. Martin RM, Kapoor KV, Wilton LV, Mann RD (1998) Underreporting of suspected adverse drug reactions to newly marketed ("black triangle") drugs in general practice: observational study. BMJ 317(7151):119-120

38. Lumley CE, Walker SR, Hall GC, Stanton N, Grob PR (1986) The under-reporting of adverse drug reactions in general practice. Pharmaceut Med 1:205-212

39. Milstien JB, Faich GA, Hsu JP, Knapp DE, Baum C, Dreis MW (1986) Factors affecting physician reporting of adverse drug reactions. Drug Inf J 20:157-164 